\title{
INDIVIDUALIZATION OF EXERTION WHILE MONITORING FUNCTIONAL STATE DURING EXERCISING
}

\author{
Živilė Kairiūkštienè ${ }^{1}$, Kristina Poderienè ${ }^{1}$, Eugenijus Trinkūnas ${ }^{1}$, Deividas Velička ${ }^{2}$, \\ Alfonsas Buliuolis ${ }^{1}$, Jonas Poderys ${ }^{1}$ \\ Lithuanian Sports University', Kaunas, Lithuania \\ Lithuanian University of Health Sciences ${ }^{2}$, Kaunas, Lithuania
}

\begin{abstract}
Background. Individualization in workloads is important in order to get optimal benefits from exercising and long-term adaptation. Heart rate (HR) monitoring during exercise can be valuable for the feedback formation. The aim of the study was to compare the calculated HR values recommended for individualization of endurance training workloads while taking into account the HR at real or relative rest.

Methods. The participating 76 healthy adults were asked to measure the pulse rate, i.e. HR self-examination at absolute and relative rest states. The results obtained during the study were analysed according to the age and gender by calculating $\mathrm{HR}_{\mathrm{Reserve}}$ and the recommended intensity of exercising at $50 \%$ of $\mathrm{HR}_{\text {Reserve }} ; 70 \%$ of $\mathrm{HR}_{\mathrm{Reserve}} ; 85 \%$ of $\mathrm{HR}_{\text {Reserve }}$.

Results. Significant difference was found when comparing the averaged values of HR obtained at the real and relative states and even greater difference was observed between relative and real resting conditions in younger groups. When calculating the recommended HR values for exercising intensity, recommended HR values significantly differ depending on whether the real or relative rest states were taken into account. This means that the algorithm for feedback formation should take into account the initial values of HR corresponding to the state of absolute rest, i.e. after 8 hours of sleep.

Conclusion. The HR at relative rest state is different to the real rest state HR and therefore the algorithm for feedback formation should take into account this difference, i.e. the corresponding correction of such HR meanings should be installed.
\end{abstract}

Keywords: health promotion, cardiovascular system, individualization.

\section{INTRODUCTION}

$\mathrm{S}$ cientists have been searching for the answer to the questions of what kind of physical activity and what intensity of exercising are the most effective for health promotion (Vainoras \& Šilanskienè, 2004; Warburton \& Bredin, 2016). Before finding the solution to these questions we must evaluate numerous findings of research as well as compare the different physical loads of fast and long-term adaptation effects. Many of the body's functional systems are very active during exercising, therefore in scientific publications there are various evaluations and suggestions on how to explore appropriate body reaction to various types of exercise (Fletcher et al., 2013; Mendonca, Fernhall, Heffernan, \& Pereira, 2009).

Individualization in workloads is important in order to get optimal benefits from exercising and long-term adaptation. Heart rate (HR) monitoring during exercising is a valuable method for the feedback (Kiss et al., 2016). Some degree of HR measuring is necessary as to maintain all requirements of methodology suggested by 
scientists (Karvonen \& Vuorimaa, 1988), i.e. to calculate HR at rest and to follow HR changes during exercising. The Karvonen formula is used to calculate the heart rate at a given percentage training intensity.

A lot of pulse monitors or feedback providing devices could be helpful in this area if they had such hind algorithms installed in their system. In case where real values of HR at rest are not know or measured the further calculations for choosing the intensity of exercising could be inaccurate. This is because the HR at state of absolute rest, i.e. after 8 hours of sleep, differs from the values calculated at state of relative rest. The aim of the study was to compare the calculated HR values recommended for individualization of endurance training workloads while taking into account the $\mathrm{HR}$ at real or relative rest.

\section{METHODS}

The participants of the study consisted of 76 healthy adults who had to perform HR selfexamination at absolute and relative rest states. In order to evaluate the difference of HR between the real and relative rest participants had to calculate their pulse for 30 seconds at each every 5 days.

The results obtained during the study were analysed according to the age and gender by performing calculations of $\mathrm{HR}_{\text {Reserve, and the }}$ recommended intensities of exercising at $50 \%$ of $\mathrm{HR}_{\text {Rezerve }} ; 70 \%$ of $\mathrm{HR}_{\text {Reserve }} ; 85 \%$ of $\mathrm{HR}_{\text {Reserve. }}$. $\mathrm{HR}_{\text {Reserve }}$ intensity was calculated using Karvonen formula (Karvonen \& Vuorimaa, 1988):

$$
\begin{array}{cc}
\mathrm{HR}_{\max }= & 220-\text { age (year) } \\
\mathrm{HR}_{\text {Reserve }}= & \mathrm{HR}_{\text {max }}-\mathrm{HR}_{\text {rest }} \\
70 \% \mathrm{HR}_{\text {Reserve }} & \mathrm{HR}_{\text {Reserve }}{\mathrm{X} 0.7+\mathrm{HR}_{\text {Rest }}} \\
85 \% \mathrm{HR}_{\text {Reserve }} & \mathrm{HR}_{\text {Reserve }} \text { X } 0.85+\mathrm{HR}_{\text {Rest }} \\
50 \% \mathrm{HR}_{\text {Reserve }} & \mathrm{HR}_{\text {Reserve }} \text { X } 0.5+\mathrm{HR}_{\text {Rest }}
\end{array}
$$

The statistical data analysis was performed using "Excel 2000" software. Data values are reported as mean values and standard deviations. Changes were evaluated using Student's $(t)$ test $(p<.05$ level of significance).

\section{RESULTS}

Significant difference was found while comparing the averaged values of HR obtained at real and relative rest state and even greater difference between relative and real resting conditions was observed in younger age groups (Figure 1).

The results were different between subjects less than 35 years old and over 35 years of age. Women's HR at real rest was $58.1 \pm 1.8$ beats / min., men's $-55.2 \pm 1.8$ beats $/ \mathrm{min}$. The values in the younger groups were lower when compared to the ones in the older groups. HR for women older than 35 years at real rest state was $62.7 \pm 3.0$ beats / min., for men older than 35 years old it was $59.1 \pm$ 1.2 beats $/ \mathrm{min}$. At relative rest the difference in values was also significant. HR at relative rest for women older than 35 years old was $70.4 \pm 2.4$ beats min., for men older than 35 years old it was $67.7 \pm 1.4$ beats $/ \mathrm{min}$. Women's relative and real HR values were higher than men's HR values, but this difference was no statistically significant $(p>.05)$.

Further calculations were aimed at calculating and comparing the values of HR at various recommended intensities of training, i.e. $50 \%$ of $\mathrm{HR}_{\text {Reserve, }}, 70 \%$ of $\mathrm{HR}_{\text {Reserve }}$, and $85 \%$ of $\mathrm{HR}_{\text {Reserve. }}$. Results showed that HR in for men younger than 35 years at real rest $(126.2 \pm 0.9-175.8 \pm 0.5$ time/ min.) and at relative rest $(132.2 \pm 0.9-177.6 \pm 0.5$ beats $/ \mathrm{min}$ ) were higher than those for men older than 35 years at real $(118.0 \pm 0.5-159.3 \pm 0.5$ beats / $\mathrm{min})$ and relative $(122.3 \pm 0.6-160.6 \pm 0.5$ beats / min.) rest in cardiovascular system's training zones. While calculating the recommended HR values in order to choose the intensity of exertion, by evaluating the real and relative rest it can be noted that the recommended HR values during exercise differed significantly.

While analysing the results we can conclude that there are similarities between men and women in age groups. Cardiovascular training zone for women younger than 35 years old which was obtained by taking into account HR values in the real rest ranged from $126.2 \pm 0.9$ up to $175.8 \pm 0.5$ beats $/ \mathrm{min}$, and obtained by taking into account HR values in the relative rest state ranged between $132.2 \pm 0.9$ up to $177.6 \pm 0.5$ beats $/ \mathrm{min}$. This comparison revealed that figures obtained by these calculations differed. The same tendency was observed while comparing the results obtained in older groups. For men older than 35 years old cardiovascular training zone according to real rest state it was $118.0 \pm$ 


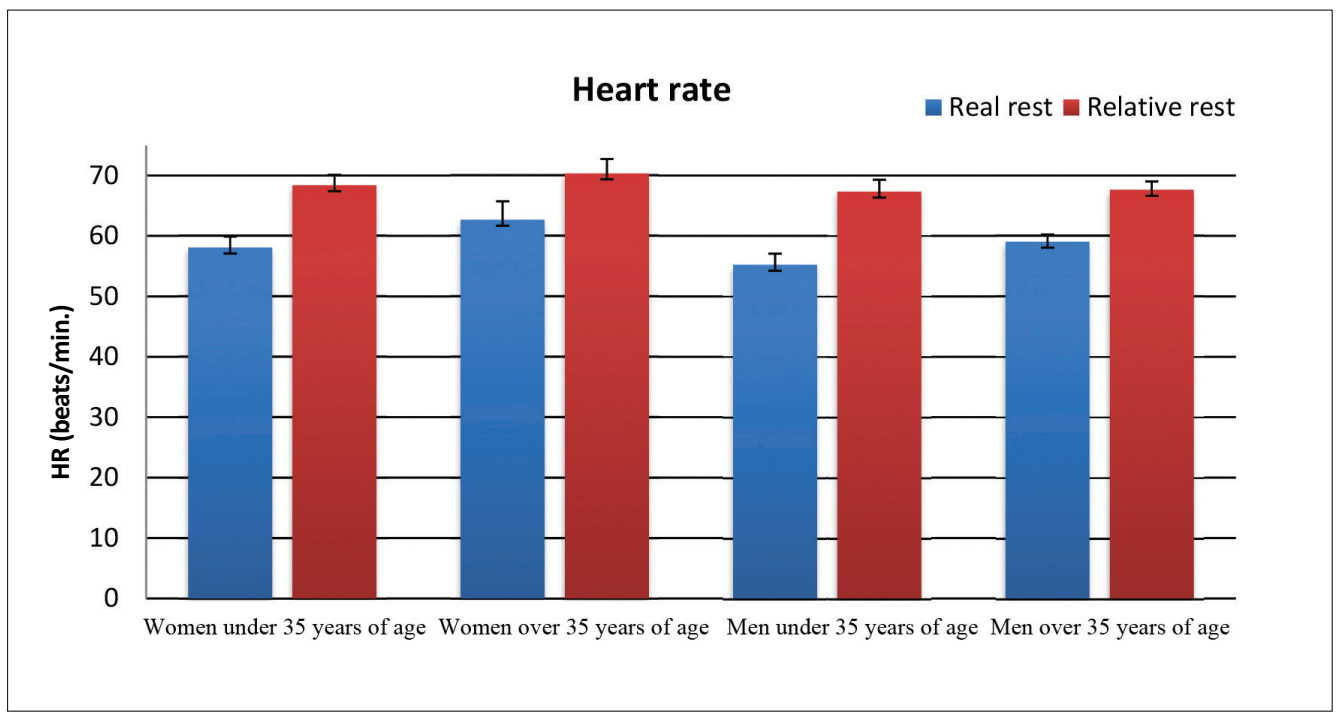

Figure 1. HR values at real and relative rest states

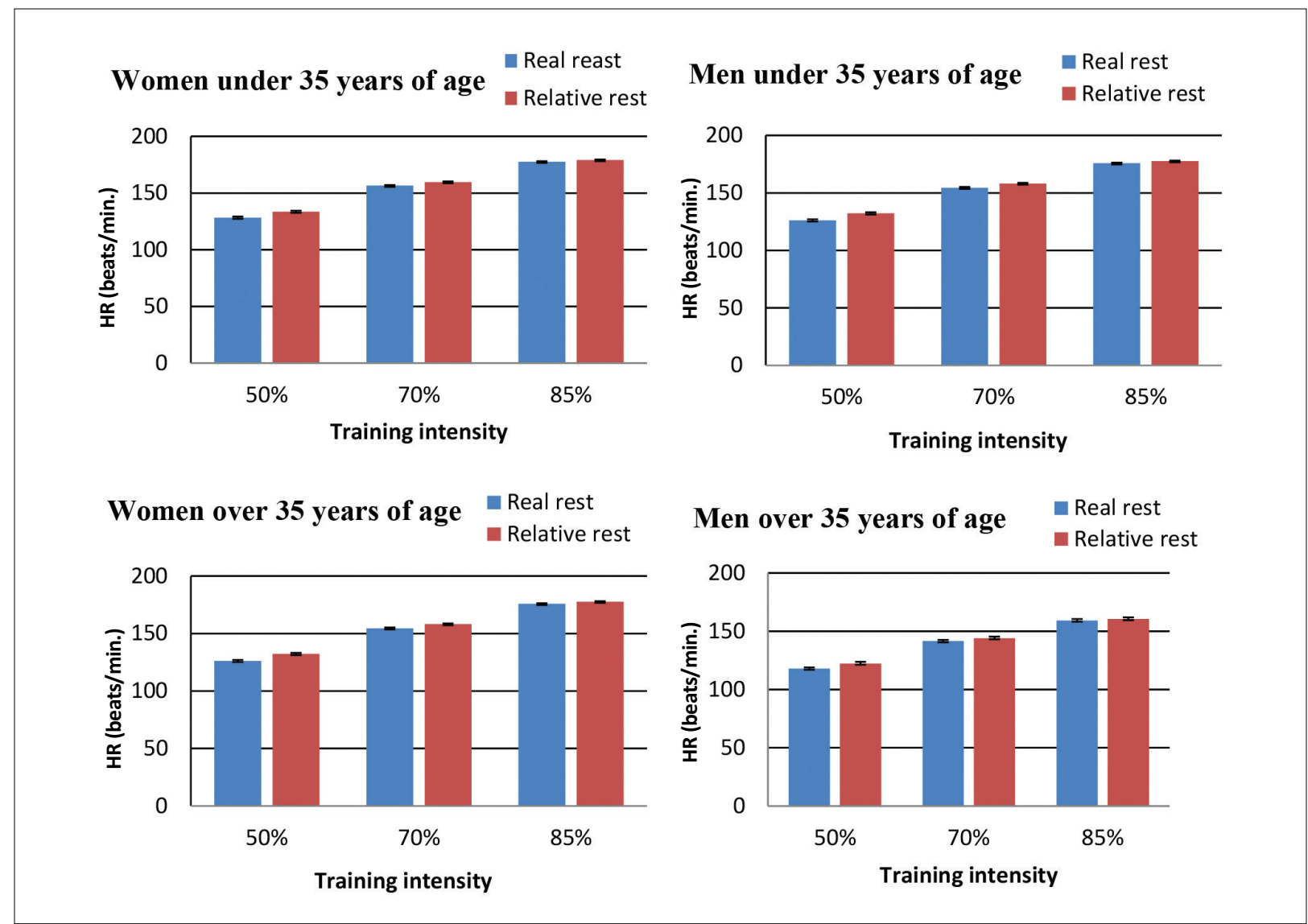

Figure 2. Values of HR calculated by taking into account real or relative rest states

$0.5-159.3 \pm 0.5$ beats $/ \mathrm{min}$ and according to the relative rest $-122.3 \pm 0.6-160.6 \pm 0.5$ beats / min. For women older than 35 years old the recommended training zone according to the real rest state was $118.8 \pm 2.1-158.1 \pm 2.2$ beats / min, while according to relative rest it was from $122.6 \pm 1.7$ to $159.2 \pm 2.1$ beats $/ \mathrm{min}$.

\section{DISCUSSION}

Health promotion by exercising is an important part of healthy life style, however it is also essential to consider the appropriate intensity of exercising (Fletcher et al., 2013; Karvonen \& Vuorimaa, 1988; Warburton \& Bredin, 2016). In 
this study we used guidelines outlined in "The Recommended Quantity and Quality of Exercise for Developing and Maintaining Cardiorespiratory and Muscular Fitness in Healthy Adults" (American College of Sports Medicine - http:// www2.gsu.edu/ wwwfit/howtoex.html). In order to choose the appropriate intensity of exercising it is necessary to take HR measurement at rest and also to monitor it during the exercise. Studies have shown that recommended HR values during exercise depend on functional preparedness and the task of the training session (Kiss et al., 2016). The intensity of exercising while HR exceed $50 \% \mathrm{HR}_{\text {Reserve }}$ could be recommended for beginners and the higher HR values should be during exercising within so called "Taget zone" while HR varies in zone from HR $70 \%$ Reserve up to HR $85 \%$ Reserve. Significant differences of these HR limits evidence that more precisely these training zones will be outlined taking into account the HR values obtained in real rest state. If the person was physically active in the past, intensity can be increased to approximately 70 $85 \% \mathrm{HR}_{\text {Reserve. }}$ If the HR is too high, the intensity of the exercise should be reduced for the reason that the endurance training is the most efficient in this target zone (Morici et al., 2016; Sebastian, Reeder, \& Williams, 2015).

Monitoring of heart rate (HR) during exercise is a valuable method for the feedback formation (Kiss et al., 2016; Mann, Lamberts, \& Lambert, 2013) and many pulse monitors or feedback providing devices can be beneficial in this area (Argha, Su, Nguyen, \& Celler, 2015). However in case of a patient deciding to participate in an exercising session without having measured his or hers real HR after of 8 hours of sleep, further calculations for choosing the intensity of exercising could be inaccurate. The results of calculations obtained by comparing values of $\mathrm{HR}$ at various recommended intensities of training, i.e. $50 \%$ of $\mathrm{HR}_{\text {Reserve }}, 70 \%$ of $\mathrm{HR}_{\text {Reserve }}$, and $85 \%$ of $\mathrm{HR}_{\text {Reserve }}$ revealed that while (if) taking into account the real or relative rest values the obtained HR values recommended for exercising significantly differ. This means that the algorithm for feedback formation installed into the monitoring system should take into account the initial values of HR corresponding to the state of absolute rest, i.e. after of 8 hours of sleep. But in case we do not have such measurements and decide to arrange a training session, a measurement of HR before exercising, i.e. at relative rest state, can be taken for this purpose; however the algorithm for feedback formation should also take this difference into account.

\section{CONCLUSION}

The HR at relative rest state is different to the real rest state HR and therefore the algorithm for feedback formation should take this difference into account, i.e. the corresponding correction of such HR values should be installed.

Acknowledgement. This work was supported by a grant from the Agency for Science, Innovation and Technology (MITA) as part of the Eureka project "Electronic wearable sport and health solutions" (ITEA2 CareWare 13034).

\section{REFERENCES}

Argha, A., Su, S. W., Nguyen, H., \& Celler, B. G. (2015). Designing adaptive integral sliding mode control for heart rate regulation during cycle-ergometer exercise using bio-feedback. In Conference proceedings: Annual International Conference of the IEEE Engineering in Medicine and Biology Society. IEEE Engineering in Medicine and Biology Society. Annual Conference, 2015, 6688-6691. doi:10.1109/EMBC.2015.7319927

Fletcher, G. F., Ades, P. A., Kligfield, P., Arena, R., Balady, G. J., Bittner, V. A., . . . Williams, M. A. (2013). Exercise standards for testing and training: A scientific statement from the American Heart Association. Circulation, 128(8), 873-934. doi:10.1161/ CIR.0b013e31829b5b44
Karvonen, J., \& Vuorimaa, T. (1988). Heart rate and exercise intensity during sports activities. Practical application. Sports Medicine, 5(5), 303-311.

Kiss, O., Sydo, N., Vargha, P., Vago, H., Czimbalmos, C., Edes, E., . . . Merkely, B. (2016). Detailed heart rate variability analysis in athletes. Clinical Autonomic Research: Official journal of the Clinical Autonomic Research Society, 26(4), 245-252. doi:10.1007/s10286016-0360-z

Mann, T., Lamberts, R. P., \& Lambert, M. I. (2013). Methods of prescribing relative exercise intensity: Physiological and practical considerations. Sports Medicine, 43(7), 613-625. doi:10.1007/s40279-0130045-x 
Mendonca, G. V., Fernhall, B., Heffernan, K. S., \& Pereira, F. D. (2009). Spectral methods of heart rate variability analysis during dynamic exercise. Clinical Autonomic Research: Official Journal of the Clinical Autonomic Research Society, 19(4), 237-245. doi:10.1007/s10286-009-0018-1

Morici, G., Gruttad'Auria, C. I., Baiamonte, P., Mazzuca, E., Castrogiovanni, A., \& Bonsignore, M. R. (2016). Endurance training: Is it bad for you? Breathe, 12(2), 140-147. doi:10.1183/20734735.007016

Sebastian, L. A., Reeder, S., \& Williams, M. (2015). Determining target heart rate for exercising in a cardiac rehabilitation program: A retrospective study. The Journal of Cardiovascular Nursing, 30(2), 164-171. doi:10.1097/JCN.0000000000000154

Vainoras, A., \& Šilanskienè, A. (2004). Fizinių krūvių veikiamo žmogaus organizmo pokyčiu vertinimo kompleksinis modelis. In J. Poderys (Ed.), Kineziologijos pagrindai (pp. 195-203). Kaunas: KMU.

Warburton, D. E., \& Bredin, S. S. (2016). Reflections on Physical Activity and Health: What Should We Recommend? The Canadian Journal of Cardiology, 32(4), 495-504. doi:10.1016/j.cjca.2016.01.024 